\title{
A New Approach on Brewer's Spent Grains Treatment and Potential Use as Lignocellulosic Yeast Cells Carriers
}

\author{
Eduardo J. Pires, * Héctor A. Ruiz, José A. Teixeira, and António A. Vicente \\ Department of Biological Engineering, University of Minho, Campus Gualtar, 4710-057, Braga, Portugal
}

ABSTRACT: The major objective of this work is to improve the pretreatments of brewer's spent grains (BSG) aiming at their use as a source for lignocellulosic yeast carriers (LCYC) production. Therefore, several pretreatments of BSG have been designed aiming at obtaining various yeast carriers, differing on their physicochemical composition. Cellulose, hemicellulose, lignin, fat, protein, and ash content were determined for crude BSG and the LCYCs. The long chain fatty acids profile for the crude BSG was also analyzed. Chemical treatments successfully produced several different LCYC based on BSG. The highest cellulose content in LCYC was achieved upon application of caustic $(\mathrm{NaOH})$ treatment during 40 min. Either caustic or combined acidcaustic treatments predominately generated hydrophobic, negatively charged LCYC. The feasibility of using BSG for LCYC production is strengthened by the fact that added-value byproduct can be extracted before the chemical treatments are applied.

KEYWORDS: Brewer's spent grains, lignocellulosic yeast carriers, cellulose, lignin, hemicellulose and treatments

\section{INTRODUCTION}

Brewer's spent grains (BSG) are the major byproduct produced by the beer industry. Nowadays, in accordance with the new tendency to find solutions for waste utilization, mainly for industry residues, ${ }^{1}$ BSG proved to be useful in applications such as human and animal nutrition, energy production, paper manufacture, as absorbent material, etc. ${ }^{2,3}$ However, in Europe, BSG is mainly used for cattle feeding and its real value as a source of marketable product seems to be underestimated.

BSG are solid remains from the wort preparation process and consist of a complex mixture of barley grain husk, pericarp, and fragments of endosperm. ${ }^{4}$ For cell immobilization itself, the grain husks are used once and they are composed mainly of a rigid matrix of cellulose $(30 \%)$, hemicellulose $(34.9 \%)$, and lignin $(17.7 \%){ }^{5}$

Continuous beer fermentation is based on a high-density yeast population, often achieved by attachment to solids substrates (carriers) and subsequent biofilm formation. Besides being food grade, the carrier chosen for this use should meet some requirements like enhanced adhesion capacity, physical resistance, low cost of production, as well as broad availability. ${ }^{6}$ Although several types of materials have been suggested for this purpose to date, including polyvinyl alcohol particles, ${ }^{7} \kappa$ carrageenan beads, ${ }^{8}$ alginate microbeads, ${ }^{9}$ and ceramic foam, ${ }^{10}$ they are relatively expensive compared to BSG. The carrier cost is extremely important and restrictive if it is to be applied on scaleup processes. Since BSG is a residue for the beer company itself, it can clearly be integrated in the continuous beer fermentation technology.

Pretreated BSG was earlier evaluated as a lignocellulosic yeast carrier (LCYC) for continuous beer fermentation, ${ }^{11-16}$ and it possesses a high yeast loading capacity triggered by biochemical and physicochemical properties of both carrier and cells.

Both caustic $(\mathrm{NaOH})$ and acid-caustic $(\mathrm{HCl}+\mathrm{NaOH})$ treatments have previously been proposed to deal with BSG during LCYC preparation, ${ }^{11,17-19}$ and they are mainly timeconsuming. Base-treated carriers are more hydrophobic if compared to acid-base treated ones, enhancing adhesion on one hand, but bieng more floatable and easily washed out from the reactor on the other hand. ${ }^{13}$ Thus, a balance between hydrophilic (cellulose) and hydrophobic (lignin) composition of carriers obtained from BSG must be idealized. A simplified caustic-based treatment could also be attractive from an economic point of view. ${ }^{13}$

The major aim of this work was to provide a fast and simple treatment for LCYC preparation from BSG. In addition, a deeper study was carried out on BSG as well as on the LCYC obtained from the treatments proposed in this work, directed to strengthen the feasibility of using this material for continuous beer production.

\section{MATERIALS AND METHODS}

Raw Material. Fresh BSG was kindly provided by UNICER Bebidas de Portugal, S.A. (S. Mamede de Infesta, Portugal) from its main beer line production. The company uses the $\mathrm{CH}-9240$ Uzwil (Buhler, Germany) grain mill to make the grist.

Previous to chemical treatments the crude BSG was sieved under water $(500 \mu \mathrm{m})$ aiming at removing the majority of residues thus obtaining a cleaner material, with higher barley husk content. After this operation, the material was placed in an oven at $50{ }^{\circ} \mathrm{C}$ until completely dry and stored at room temperature for further use.

Lignocellulosic Yeast Carrier (LCYC) Preparation. In order to be used as yeast carrier, the washed BSG received a series of different chemical treatments (Table 1 summarizes the conditions used), as well as the treatments proposed in the literature. ${ }^{11}$ Aimed at comparing the final yield of treated material, crude BSG (nonwashed) received the same treatments. For all circumstances, $50 \mathrm{~g}$ of dried BSG was treated using several combinations of $\mathrm{NaOH}$ and/or $\mathrm{HCl}$ (Panreac) concentrations, always in a 1:15 (w/v) ratio. All treatments were done in triplicate, and treated material was dried and stored at room temperature for subsequent chemical analysis.

Received: January 23, 2012

Revised: $\quad$ May 4, 2012

Accepted: May 25, 2012

Published: May 25, 2012 
Table 1. Chemical Treatments Applied on Brewers Spent Grains (BSG) for Lignocellulosic Yeast Carrier (LCYC) Preparation

\begin{tabular}{|c|c|}
\hline treatment & description \\
\hline caustic $^{a}$ & $2 \% \mathrm{NaOH}, 120 \mathrm{rpm}, 30^{\circ} \mathrm{C}, 24 \mathrm{~h}$ \\
\hline acid-caustic ${ }^{a}$ & $\begin{array}{l}\left(3 \% \mathrm{HCl}, 60^{\circ} \mathrm{C}, 2.5 \mathrm{~h}\right)+\left(2 \% \mathrm{NaOH}, 120 \mathrm{rpm}, 30^{\circ} \mathrm{C} \text {, }\right. \\
\quad 24 \mathrm{~h})\end{array}$ \\
\hline fast caustic & $3 \% \mathrm{NaOH}, 70{ }^{\circ} \mathrm{C}, 20 \mathrm{~min}$ \\
\hline $\begin{array}{l}\text { double caustic } 3 \% \text { and } \\
6 \%\end{array}$ & $\begin{array}{l}\left(3 \% \mathrm{NaOH}, 70{ }^{\circ} \mathrm{C}, 20 \mathrm{~min}\right)+\left(6 \% \mathrm{NaOH}, 90^{\circ} \mathrm{C}, 20\right. \\
\min )\end{array}$ \\
\hline $\begin{array}{l}\text { double caustic } 3 \% \text { and } \\
3 \%\end{array}$ & $\begin{array}{l}\left(3 \% \mathrm{NaOH}, 70{ }^{\circ} \mathrm{C}, 20 \mathrm{~min}\right)+\left(3 \% \mathrm{NaOH}, 90^{\circ} \mathrm{C}, 20\right. \\
\min )\end{array}$ \\
\hline $\begin{array}{l}\text { double caustic } 3 \% \text { and } \\
\quad 1 \%\end{array}$ & $\begin{array}{l}\left(3 \% \mathrm{NaOH}, 70{ }^{\circ} \mathrm{C}, 20 \mathrm{~min}\right)+\left(1 \% \mathrm{NaOH}, 90^{\circ} \mathrm{C}, 20\right. \\
\min )\end{array}$ \\
\hline double caustic $0.5 \%$ & $\begin{array}{l}\left(0.5 \% \mathrm{NaOH}, 70{ }^{\circ} \mathrm{C}, 20 \mathrm{~min}\right)+\left(0.5 \% \mathrm{NaOH}, 90{ }^{\circ} \mathrm{C},\right. \\
20 \mathrm{~min})\end{array}$ \\
\hline fast caustic and acid & $\begin{array}{l}\left(1 \% \mathrm{NaOH}, 70{ }^{\circ} \mathrm{C}, 20 \mathrm{~min}\right)+\left(1 \% \mathrm{HCl}, 70{ }^{\circ} \mathrm{C}, 20\right. \\
\min )\end{array}$ \\
\hline
\end{tabular}

Chemical Treatments. The treatments proposed in the literature to deal with BSG are mainly time-consuming $(3-26 \mathrm{~h})^{11,17-19}$ and a faster and equally efficient treatment is needed. The pulping industry uses modified Kraft pulping processes for cellulose purification from wood. However, the Kraft method and its enhanced varieties use high temperatures and very strong caustic solutions composed mainly of $\mathrm{NaOH}$ and $\mathrm{Na}_{2} \mathrm{~S},{ }^{20}$ which would probably destroy BSG completely. Thus, double caustic treatments have heuristically been proposed to fit a simpler material like BSG.

Physicochemical Characterization of LCYC. Cellulose and Hemicellulose Characterization. All carriers and washed BSG were assessed for sugar polymer content through high-performance liquid chromatography $(\mathrm{HPLC})$ using a Metacarb $67 \mathrm{H}$ column $(300 \times 6.5$ $\mathrm{mm}$, Varian) preheated to $60{ }^{\circ} \mathrm{C}$ by a thermostated column compartment (Chrompack Instruments AG, Neuheim, Switzerland). The mobile phase $\left(\mathrm{H}_{2} \mathrm{SO}_{4} 0.005 \mathrm{~mol} \cdot \mathrm{L}^{-1}\right)$ was pumped at a flow rate of $0.7 \mathrm{~mL} \cdot \mathrm{min}^{-1}$ through a JASCO $880 \mathrm{PU}$ pump. Samples were automatically injected (JASCO Intelligent Sampler AS 2057 Plus). The methods and data analyses were carried out according to Ruiz et al. ${ }^{21}$ Briefly, approximately $0.5 \mathrm{~g}$ of each dried carrier was treated with $72 \% \mathrm{H}_{2} \mathrm{SO}_{4}$ (Sigma-Aldrich) for $1 \mathrm{~h}$, at $30{ }^{\circ} \mathrm{C}$, under agitation. The treated material then settled in $500 \mathrm{~mL}$ autoclavable glass flasks (Simax) containing $148.67 \mathrm{~g}$ of pure water and was autoclaved for $1 \mathrm{~h}$ at $121^{\circ} \mathrm{C}$. The flasks contents were then filtered through a $20 \mu \mathrm{m}$ polyester mesh. Solids were held in reserve for lignin content determination, while the liquid was placed in vials for assessment of sugars.

Klason Lignin Determination. The solids obtained after the treatment with sulfuric acid, as described above, are composed mainly of lignin and ash. Thus, these solids were dried in an oven at $105{ }^{\circ} \mathrm{C}$ for $24 \mathrm{~h}$. After that, dry weight was determined followed by combustion of the material in a muffle at $600{ }^{\circ} \mathrm{C}$ for $8 \mathrm{~h}$ for ash weight determination. The Klason lignin fraction is the difference in weight between the dry weight and ash divided by the carrier dry weight before digestion.

Contact Angle. Carriers and nontreated barley husks from washed BSG were clamped one by one to glass slides with double-sided tape, with the aid of a stereoscopic microscope. Contact angles of three different pure liquids (water, formamide, and $\alpha$-bromonaphthalene) were assessed by the sessile drop technique with a drop volume varying from 0.1 to $0.3 \mu \mathrm{L}$, using a contact angle apparatus (OCA 20, Dataphysics). At least 30 readings were determined for each sample and liquid, at $25^{\circ} \mathrm{C}$. All data were processed and calculated according to the method of van Oss et al. ${ }^{22}$

Zeta Potential. Carriers and washed BSG were milled to powder with an agate ball mill (Retsch) and sieved through a $90 \mu \mathrm{m}$ mesh sieve. Approximately $0.1 \mathrm{~g}$ of sieved powder was suspended in $50 \mathrm{~mL}$ of $\mathrm{KNO}_{3}$ $0.01 \mathrm{~mol} \cdot \mathrm{L}^{-1}$ solution and filtered through Whatman filter paper grade no. 1 with a particle retention size of $11 \mu \mathrm{m}$. The $\mathrm{pH}$ was adjusted to 5 and the suspension was used to fill the electrophoresis cells for zeta potential determination with a Zetasizer Nano ZS (Malvern Instru- ments). Five repetitions of 50 readings for each sample were carried out and the average zeta potential was calculated for each one of them.

Total Fat Analysis. The Soxtec method was performed for total fat content determination from carriers and crude and washed BSG accordingly to the manufacturer's protocol (Tecator). A Soxtec System HT2 1045 extraction unit helped by the Soxtec System HT service unit (Tecator) was used in the process. Approximately $1 \mathrm{~g}$ of each material was used in the extraction, and diethyl ether (Sigma-Aldrich) was used as solvent. All extractions were carried out in triplicate for each material.

Protein Content. The Kjeldahl technique was implemented for total nitrogen determination of carriers and crude and washed BSG. Digestion was carried out in a Digestion System 201015 digester (Tecator) while the distillation took place in a Kjeltec system 1026 distilling unit (Tecator). Briefly, approximately $0.1 \mathrm{~g}$ of each material was digested with $10 \mathrm{~mL}$ of $96 \%$ sulfuric acid (Sigma-Aldrich), using selenium (Kejeltabs, Thompson \& Capper LTD) as catalyst at $350{ }^{\circ} \mathrm{C}$. Distillation was further performed and a $40 \mathrm{~g} \cdot \mathrm{L}^{-1}$ boric acid (Fisher Scientific, UK) solution containing the $\mathrm{pH}$ indicators Methyl Red (Acros Organics) and Bromocresol Green (Acros Organics) was used as receiving solution. Back-titration was then executed using a 0.025 $\mathrm{mol} \cdot \mathrm{L}^{-1}$ sulfuric acid solution. Experiments were done in triplicate for all materials.

Long Chain Fatty Acids (LCFA). Lipids were extracted by the Soxtec (Tecator) method from approximately $5 \mathrm{~g}$ of dried crude BSG. LCFA composition was analyzed by a pre-established method. ${ }^{23}$ Dichloromethane (DCM) standard solutions were used to make a calibration curve for each of the following LCFA: lauric (C12:0), myristic (C14:0), palmitic (C16:0), palmitoleic (C16:1), stearic (C18:0), oleic (C18:1), and linoleic (C18:2) acids. The synthetic fatty acid pentadecanoic acid (C15:0) was used as internal standard. Both DCM and all LCFA mentioned were acquired from Fluka (Buchs, Switzerland). The LCFA analysis was done by gas chromatography (GC) (CP-9001, Chrompack) with an eq.CP-Sil 52CB $30 \mathrm{~m} \times 0.32 \mathrm{~mm} \times 0.25 \mu \mathrm{m}$ Tr-wax column (Teknokroma). Helium was used as carrier gas at 1.0 $\mathrm{mL} \cdot \mathrm{min}^{-1}$ flow rate.

Statistical Analyses. Statistical analyses were performed using analysis of variance (ANOVA). The multiple comparison test $(\alpha=0.05)$ was used to determine any significance of differences between specific means (Matlab, version 7.6.0, R2008a software).

\section{RESULTS AND DISCUSSION}

Carriers' Yield. The bulk yields for the chemical treatments are displayed in Table 2. Treatments applied on washed BSG

Table 2. Bulk Yield of the Chemical Treatments

\begin{tabular}{lcc} 
& \multicolumn{2}{c}{${\text { yield }(\%)^{a}}^{c}$ treatment $^{c}$} \\
\cline { 2 - 3 } caustic $^{b}$ & 10 & washed \\
acid-caustic $^{b}$ & 8.7 & 29.6 \\
fast caustic $_{\text {double caustic 3\% and 6\% }}$ & 9.1 & 15.1 \\
double caustic 3\% and 3\% & 5.9 & 30 \\
double caustic 3\% and 1\% & 6.8 & 20.1 \\
double caustic 0.5\% & 8 & 22.7 \\
fast caustic and acid & 15.9 & 25.2 \\
\end{tabular}

${ }^{a}$ Weight of carrier obtained from $100 \mathrm{~g}$ of BSG. ${ }^{b}$ Methods performed by Brányik et al. ${ }^{11}$

were expressively $(p<0.05)$ more efficient if compared to crude ones. The treatments proposed in the literature ${ }^{11}$ were successfully replicated in this work and strongly support the yield presented in Table 2. Undoubtedly the washing step played an important role in treatment performance, possibly because the washed BSG has a higher ratio of barley husks (w/w). Thus, effectively alkali is more available to act in the husks if no other 
Table 3. Average Content Percentage from Crude, Washed BSG and Carriers Obtained from Washed BSG ${ }^{a}$

\begin{tabular}{|c|c|c|c|c|c|c|}
\hline material & fat $(\%)$ & protein (\%) & lignin (\%) & cellulose (\%) & hemicellulose (\%) & ash (\%) \\
\hline crude & $10.51 \mathrm{~A}$ & $39.08 \mathrm{~A}$ & $25.62 \mathrm{~A}$ & $20.97 \mathrm{~A}$ & $15.18 \mathrm{~A}$ & $2.21 \mathrm{~A}, \mathrm{~B}, \mathrm{C}, \mathrm{E}, \mathrm{F}$ \\
\hline washed BSG & $3.85 \mathrm{~B}$ & $30.06 \mathrm{~B}$ & $31.01 \mathrm{~B}$ & $19.21 \mathrm{~A}$ & $8.26 \mathrm{~B}$ & $2.51 \mathrm{~A}, \mathrm{~B}, \mathrm{C}, \mathrm{E}, \mathrm{F}$ \\
\hline caustic $^{b}$ & $0.74 \mathrm{C}, \mathrm{G}, \mathrm{H}, \mathrm{I}, \mathrm{J}$ & $3.76 \mathrm{C}, \mathrm{E}$ & 22.65 A,C,D & $35.26 \mathrm{~B}$ & $11.45 \mathrm{C}$ & 2.97 A,B,C,E,J \\
\hline double caustic $0.5 \%$ & $1.81 \mathrm{D}, \mathrm{E}, \mathrm{I}$ & 1.43 D,F,G,H,I,J & 22.99 A,C,D & $35.82 \mathrm{~B}$ & $12.89 \mathrm{D}$ & 1.02 D,F,G,H,I \\
\hline fast caustic and acid & 1.84 D,E,I & $3.31 \mathrm{C}, \mathrm{E}, \mathrm{J}$ & 27.79 A,B & $40.17 \mathrm{C}$ & $7.12 \mathrm{E}$ & 2.49 A,B,C,E,F \\
\hline fast caustic & $0.47 \mathrm{C}, \mathrm{F}, \mathrm{G}, \mathrm{H}, \mathrm{J}$ & 1.76 D,F,G,H,I,J & $19.39 \mathrm{C}, \mathrm{E}$ & $41.38 \mathrm{C}, \mathrm{D}$ & $10.17 \mathrm{~F}$ & 1.56 A,B,D,E,F,G,H,I \\
\hline double caustic $3 \%$ and $1 \%$ & $0.6 \mathrm{C}, \mathrm{F}, \mathrm{G}, \mathrm{H}, \mathrm{I}, \mathrm{J}$ & $0.91 \mathrm{D}, \mathrm{F}, \mathrm{G}, \mathrm{H}, \mathrm{I}, \mathrm{J}$ & 20.14 C,D,E & $45.14 \mathrm{D}$ & $8.15 \mathrm{~B}$ & 0.98 D,F,G,H,I \\
\hline double caustic $3 \%$ and $3 \%$ & 0.69 C,F,G,H,I,J & 0.97 D,F,G,H,I,J & $28.39 \mathrm{C}, \mathrm{D}, \mathrm{E}$ & $50.03 \mathrm{E}$ & $7.87 \mathrm{~B}, \mathrm{E}$ & $0.77 \mathrm{D}, \mathrm{F}, \mathrm{G}, \mathrm{H}, \mathrm{I}$ \\
\hline double caustic $3 \%$ and $6 \%$ & 1.18 C,D,E,G,H,I & 0.68 D,F,G,H,I,J & $16.25 \mathrm{C}, \mathrm{E}$ & $55.64 \mathrm{~F}$ & $6.29 \mathrm{E}$ & $0.75 \mathrm{D}, \mathrm{F}, \mathrm{G}, \mathrm{H}, \mathrm{I}$ \\
\hline acid-caustic $^{b}$ & $0.25 \mathrm{C}, \mathrm{F}, \mathrm{G}, \mathrm{H}, \mathrm{J}$ & $2.01 \mathrm{D}, \mathrm{E}, \mathrm{F}, \mathrm{G}, \mathrm{H}, \mathrm{I}, \mathrm{J}$ & $21.19 \mathrm{C}, \mathrm{D}, \mathrm{E}$ & $61.09 \mathrm{G}$ & $0 \mathrm{G}$ & $3.74 \mathrm{C}, \mathrm{J}$ \\
\hline
\end{tabular}

residue is present to compete with it. Hence, a simple washing step applied to BSG could reflect directly in a final lower cost of carriers' production by savings in the total amount of reagents needed in the subsequent processes. In addition, the residual washed material (approximately $80 \%$ of total material), which was taken apart from the treatment, could be used for other purposes, such as animal nutrition (as stated, this is the major destination of BSG), energy production, and in biotechnological processes as substrate for microorganisms and enzyme production. ${ }^{2,3}$

Chemical Analyses of BSG and LCYCs. The composition of BSG may vary with barley variety, time of harvest, and characteristics of hops and other adjuncts added during the brewing process; changes may also occur due to brewery technology, even within the same beer industry. ${ }^{24}$ The average chemical compositions for the crude washed (nontreated) BSG and LCYCs are shown in Table 3.

Considering the concentrations $\left(\mathrm{g} \cdot \mathrm{L}^{-1}\right)$ of monosaccharides (mainly glucose, xylose, and arabinose) and considering correction factors like sugar degradation, density, water evaporation, and stoichiometry, it is possible to calculate the amount of polymer that has been hydrolyzed to monomers for the given sample. ${ }^{21}$ Cellulose, hemicellulose, and lignin composition for the crude BSG from UNICER strongly agrees with data present in the literature. ${ }^{2,3,25}$ The present pioneering work on chemical analysis of LCYCs will allow a better understanding of yeast adhesion to lignocellulosic matrices in further studies. Caustic and acid-caustic treatments, ${ }^{11}$ for example, greatly differed in lignocellulosic composition. The former treatment resulted in almost half of the cellulose content (in \%) than the last one. As already reported for the washing step, it is possible that the acid treatment removes most of the nonlignocellulosic residues that would compete directly with the effective alkali, which could then more efficiently remove lignin from the husks. In the first stage of Kraft pulping, for example, only a small amount of lignin is removed from the wood because more than $40 \%$ of effective alkali is consumed by other residues, while in the second stage more than $65 \%$ of lignin is extracted. $^{20,26}$ To reinforce this fact, the cellulosic content of carriers obtained by the acid-caustic treatment ${ }^{11}$ from crude (nonwashed) BSG was also measured $(46.1 \pm 0.2 \%)$. This clearly demonstrates that a direct chemical treatment on crude residuerich BSG greatly reduces the treatments' efficiency, once the same method applied to washed BSG achieved $61.1 \pm 2.27 \%$ of cellulose content. Still, either acid-caustic or caustic treatments ${ }^{11}$ take more than $24 \mathrm{~h}$ to obtain the final carrier; such a long treatment time would be unacceptable for industrial production. Double caustic (3\% and 6\%) treatment on the other hand allowed a similar $(55.6 \pm 0.6 \%)$ cellulose content to be achieved in just $40 \mathrm{~min}$.

The average fat, protein, and ash percentages of crude BSG agree with previous reports. ${ }^{2,3,24,27}$ All treatments almost completely removed fat and protein residues from BSG. Therefore, the remaining material was nearly a pure lignocellulosic rigid substance that can be further used as yeast carrier. The effective removal of these substances is essential if this material is to be applied to continuous beer production as the residual fat or protein contents could easily interfere with beer flavor and/or turbidity. ${ }^{28-30}$

Both saturated and unsaturated LCFA are present in the lipid profile of BSG from UNICER. The prevailing LCFA on BSG are linoleic acid (55.5\%) and palmitic acid (32.5\%) (Figure 1). Not

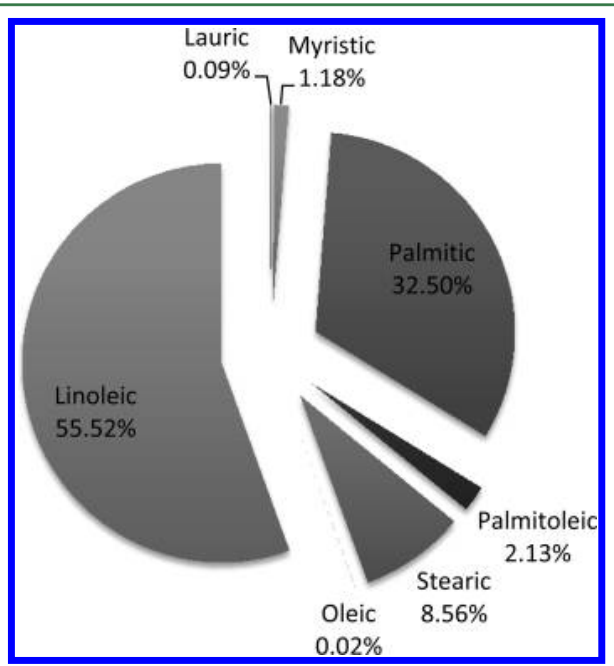

Figure 1. Long chain fatty acids profile from brewer's spent grains. The concentrations of LCFAs in grams per liter of liquid oil extracted are as follows: lauric acid, $0.06 \mathrm{~g} / \mathrm{L}$; myristic acid, $0.77 \mathrm{~g} / \mathrm{L}$; palmitic acid, 20.99 $\mathrm{g} / \mathrm{L}$; palmitoleic acid, $1.38 \mathrm{~g} / \mathrm{L}$; stearic acid, $5.53 \mathrm{~g} / \mathrm{L}$; oleic acid, $0.01 \mathrm{~g} /$ $\mathrm{L}$; and linoleic acid, $35.86 \mathrm{~g} / \mathrm{L}$.

surprisingly, these LCFA are predominant in the preboil wort. ${ }^{28,31,32}$ Linoleic acid has earlier been reported to play a major role in the detrimental increase of wort turbidity, thus affecting the end product quality. ${ }^{28-30}$ Bad for brewing on the one hand, yet good as an added-value substance on the other hand, these oils could be extracted from BSG previous to the chemical treatment, purified, and sold as such; this is, however, out of the scope of the present work.

LCYC. The use of lignocellulosic materials as yeast carriers is far from being a modern science, as several sources of this 


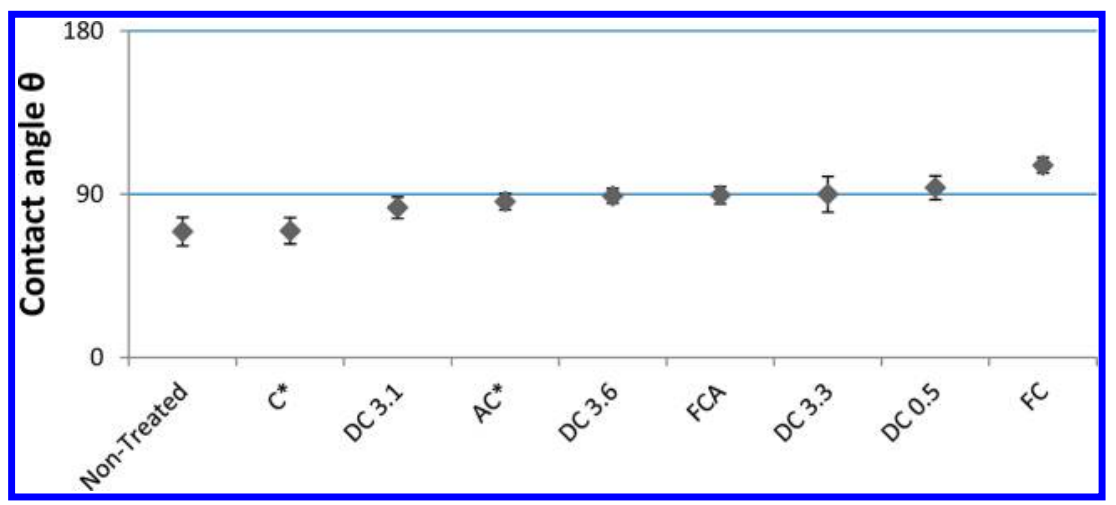

Figure 2. Average contact angle between pure water and nontreated barley husks from washed BSG and carriers. From the left to the right: nontreated barley husks from washed BSG; caustic ${ }^{11}$ treatment applied to washed BSG $\left(C^{*}\right)$, double caustic $3 \%$ and $1 \%$ (DC 3.1 ), acid-caustic ${ }^{11}$ treatment applied to washed BSG, double caustic 3\% and 6\% (DC 3.6), fast caustic and acid (FCA); double caustic 3\% and 3\% (DC 3.3); double caustic 0.5\% (DC 0.5), and fast caustic (FC).

material for yeast immobilization have been evaluated since long ago. ${ }^{11,17,33}$ The use of BSG as a source of LCYC was first implemented for continuous beer making ${ }^{12,16}$ and more recently for wine production. ${ }^{19}$

The contact angle is the angle at which the liquid-vapor meets the solid-liquid interface. Since the tendency for a drop of liquid to spread over a plane solid surface increases as the contact angle $\theta$ decreases, the contact angle provides a useful, inverse measure of wettability. ${ }^{34}$ In general, if the contact angle is lower than $90^{\circ}$, the surface is known to be wettable or hydrophilic, while if the contact angle is higher than $90^{\circ}$, the surface is called hydrophobic and is less prone to wet. For practical purposes, Figure 2 outlines a $90^{\circ}$ line, which didactically suggests the wettability limit for the described treatments. Each value represents the average contact angle from 30 readings of pure water droplets on the carrier surface. The same problem reported by Brányik et al. ${ }^{13}$ regarding contact angle measurements at the carriers' surface was experienced in this work. The sessile drop method usually needs a large flat surface where the liquid drop can rest and the contact angle may be measured. Lignin works as a cement matrix that holds cellulose fibers together. The caustic treatment removes the lignin present in the barley husks, greatly increasing the surface roughness by exposing the cellulose fibers. The rough surface now tends to spread the drop by capillarity and this may cause a reading bias. To smooth this bias the discrepant five highest and five lowest contact angle values were discarded. The fast caustic treated carrier was the most $(p<0.05)$ hydrophobic, while the nontreated barley husks seem to be slightly hydrophilic. Caustic ${ }^{11}$ treatment applied on washed BSG was also somewhat hydrophilic. All other treatments showed no significant $(p>$ 0.05 ) differences and are grouped around the hydrophobic/ hydrophilic line. Hydrophobicity is known to enhance yeast adhesion and biofilm formation, ${ }^{35-37}$ but this parameter may be tricky for continuous beer production, as unbalanced (in terms of lignin/cellulose content) hydrophobic carriers tend to float and may easily be washed out from the reactor. ${ }^{13}$

Figure 3 shows the influence of lignocellulosic composition on carriers' surface tension. Although no strong correlation has been found between lignin or cellulose contents on carriers' surface tension, possibly due to the lack of homogeneity of the materials used (from industrial origin), it is clear that the presence of cellulose and lignin do contribute to changes in surface properties of the carrier, which is fundamental when considering yeast cells adhesion to surfaces. ${ }^{13,34}$
The average zeta potential for the nontreated barley husks from washed BSG is very close to zero $(-0.07 \pm 0.12 \mathrm{mV})$. All treatments have slightly reduced the zeta potential of carriers' surface to negative values (Figure 4). The lower zeta potential

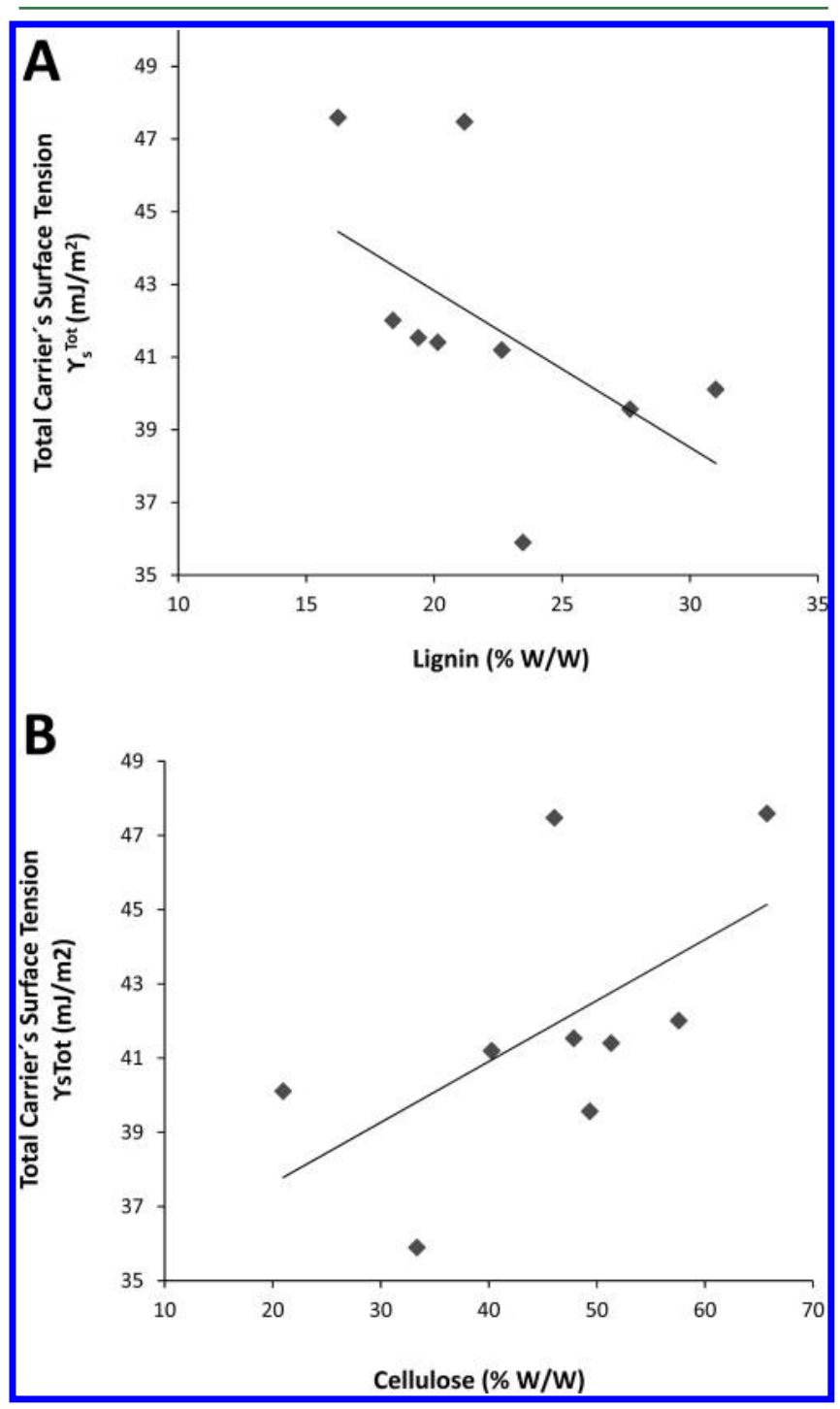

Figure 3. Changes of the total surface tension of carriers as a function of their content in (A) lignin and (B) cellulose. 


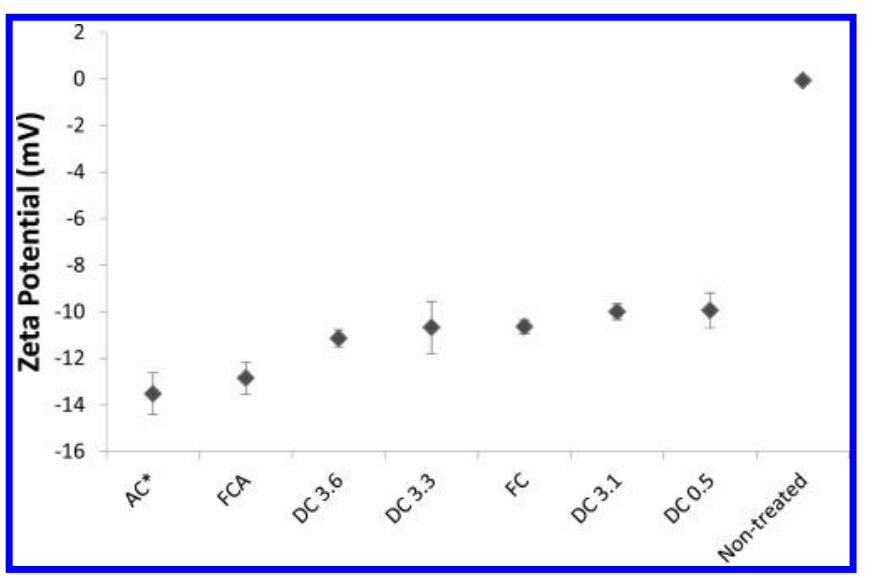

Figure 4. Zeta potential of carriers and nontreated barley husks. From left to right: acid-caustic (AC), ${ }^{11}$ fast caustic and acid (FCA), double caustic 3\% and 6\% (DC 3.6), double caustic 3\% and 3\% (DC 3.3), fast caustic (FC), double caustic $3 \%$ and $1 \%$ (DC 3.1), double caustic $0.5 \%$ (DC 0.5), and nontreated barley husks from washed BSG.

values $(p<0.05)$ were observed for acid-treated carriers with both acid-caustic ${ }^{11}(-13.52 \pm 0.9 \mathrm{mV})$ and fast caustic and acid $(-12.84 \pm 0.69 \mathrm{mV})$, but they are statistically similar. This suggests that acid treatments may not be a good choice if this material is to be applied to cell immobilization. Still, posttreatments with positively charged substances are known to help with this matter. ${ }^{11}$ All other treatments had no significant $(p>$ 0.05 ) influence on the values of the carriers' zeta potential, which varied between -9.94 and $-11.14 \mathrm{mV}$.

Back in 2004, Branyik et al. ${ }^{13}$ already emphasized the need for a simpler caustic treatment: “... the equilibrium between the carrier's hydrophobic (cell adhesion sites) and hydrophilic (wettable) properties should be maintained by shortening the acidic hydrolysis of the spent grains. The resulting simplified preparation procedure, consisting only of the base treatment, will have also an attractive economic feature.” Thus, the current work successfully established several simpler and faster treatments for LCYC preparation. Although the highest percentage of cellulose was achieved with the acid-caustic treatment ${ }^{11}$ applied on washed BSG, double caustic 3\% and 6\% must be highlighted for faster LCYC achievement at similar yields of cellulose content.

The present work evaluated several chemical treatments for fast production of LCYCs in view of their use in scaled-up processes and further implementation in continuous beer production. The key element for using BSG in LCYC production goes beyond the contents of lignocellulosic material in barley husks, once this byproduct is rich in other components that would be wasted by direct treatment of the raw BSG. Thus, an extraction of fat and protein contents from BSG before the chemical treatment for LCYC production is highly recommended, as it could greatly add value to the process as a whole. This added-value would lay both in the improvement of the yield of the LCYC production process and in the extraction of highvalue compounds from the rejected protein/lipid fraction.

\section{AUTHOR INFORMATION}

\section{Corresponding Author}

*Phone: (+351) 253601962. Fax: (+351) 253678986. Email:eduardo.pires@deb.uminho.pt.

\section{Funding}

E.P. gratefully acknowledges the Fundação para a Ciência e a Tecnologia (FCT, Portugal) for Ph.D. fellowship support
(SFRH/BD/61777/2009) and H.A.R. thanks to the Mexican Science and Technology Council (CONACYT, Mexico) for Ph.D. fellowship support (CONACYT grant number 213592/ 308679). The financial contribution of the EU FP7 project EcoBioCAP-Ecoefficient Biodegradable Composite Advanced Packaging, Grant Agreement No. 265669 is also gratefully acknowledged.

\section{Notes}

The authors declare no competing financial interest.

\section{ACKNOWLEDGMENTS}

The brewer's spent grain supplied by UNICER Bebidas de Portugal, S.A. (S. Mamede de Infesta, Portugal) is gratefully acknowledged.

\section{REFERENCES}

(1) Orzua, M. C.; Mussatto, S.; Contreras-Esquivel, J. C.; Rodriguez, R.; de la Garza, H.; Teixeira, J.; Aguilar, C. N. Exploitation of agro industrial wastes as immobilization carrier for solid-state fermentation. Ind. Crop Prod. 2009, 30, 24-27.

(2) Mussatto, S.; Dragone, G.; Roberto, I. Brewers' spent grain: Generation, characteristics and potential applications. J. Cereal Sci. 2006, $43,1-14$.

(3) Mussatto, S.; Fernandes, M.; Rocha, G. J. M.; Orfão, J. J. M.; Teixeira, J.; Roberto, I. Production, characterization and application of activated carbon from brewer's spent grain lignin. Bioresource Technol. 2010, 101, 2450-7.

(4) Forssell, P.; Kontkanen, H.; Schols, H. A.; Hinz, S.; Eijsink, V. G. H.; Treimo, J.; Robertson, J. A.; Waldron, K. W.; Faulds, C. B.; Buchert, $\mathrm{J}$. Hydrolysis of brewers' spent grain by carbohydrate degrading enzymes. J Inst Brew 2008, 114, 306-314.

(5) Palmarola-adrados, B.; Galbe, M.; Zacchi, G. Pretreatment of barley husk for bioethanol production. J. Chem. Technol. Biotechnol. 2005, 91, 85-91.

(6) Cheng, K.-C.; Demirci, A.; Catchmark, J. M. Advances in biofilm reactors for production of value-added products. Appl. Microbiol. Biot. 2010, 87, 445-56.

(7) Bezbradica, D.; Obradovic, B.; Leskosek-cukalovic, I.; Bugarski, B.; Nedovic, V. Immobilization of yeast cells in PVA particles for beer fermentation. Proc. Biochem. 2007, 42, 1348-1351.

(8) Decamps, C.; Norton, S.; Nationale, E.; Cedex, N.; Neufeld, R. J. Continuous pilot plant scale immobilization of yeast in $\kappa$-carrageenan gel beads. AIChE J. 2004, 50, 1599-1605.

(9) Nedovic, V. A.; Obradovic, B.; Leskos, I. Electrostatic generation of alginate microbeads loaded with brewing yeast. Process Biochem. 2001, $37,17-22$.

(10) Cheng, J.; Su, Z.; Liang, C.; Ye, Q.Immobilization technology of Saccharomyces cerevisiae in foam ceramic. China Brew. 2009, doi CNKI:SUN:ZNGZ.0.2009-03-043.

(11) Brányik, T.; Vicente, A.; Cruz, J. M.; Teixeira, J. Spent grains-A new support for brewing yeast immobilisation. Biotechnol. Lett. 2001, 23, 1073-1078.

(12) Brányik, T.; Vicente, A.; Cruz, J. M.; Teixeira, J. Continuous Primary Beer Fermentation with Brewing Yeast Immobilized on Spent Grains. Scan Electron Microsc. 2002, 108, 410-415.

(13) Brányik, T.; Vicente, A.; Oliveira, R.; Teixeira, J. Physicochemical surface properties of brewing yeast influencing their immobilization onto spent grains in a continuous reactor. Biotechnol. Bioeng. 2004, 88, 84-93.

(14) Brányik, T.; Vicente, A.; Kuncová, G.; Podrazký, O.; Dostálek, P.; Teixeira, J. Growth model and metabolic activity of brewing yeast biofilm on the surface of spent grains: A biocatalyst for continuous beer fermentation. Biotechnol. Prog. 2004, 20, 1733-40.

(15) Brányik, T.; Vicente, A.; Dosta, P.; Teixeira, A. Continuous beer fermentation using immobilized yeast cell bioreactor systems. Biotechnol. Prog. 2005, 21, 653-663. 
(16) Brányik, T.; Silva, D. P.; Vicente, A.; Lehnert, R.; e Silva, J. B. A.; Dostálek, P.; Teixeira, J. Continuous immobilized yeast reactor system for complete beer fermentation using spent grains and corncobs as carrier materials. J. Ind. Microbiol. Biot. 2006, 33, 1010-8.

(17) Bardi, E. P.; Koutinas, A. A. Immobilization of yeast on delignified cellulosic material for room temperature and low-temperature wine making. J. Agric. Food Chem. 1994, 42, 221-226.

(18) Kopsahelis, N.; Kanellaki, M.; Bekatorou, A. Food chemistry low temperature brewing using cells immobilized on brewer's spent grains. Food Chem. 2007, 104, 480-488.

(19) Tsaousi, K.; Velli, A.; Akarepis, F.; Bosnea, L.; Drouza, C.; Koutinas, A. A.; Bekatorou, A. Low-temperature winemaking by thermally dried immobilized yeast on delignified brewer's spent grains. Food Technol. Biotechnol. 2011, 49, 379-384.

(20) Santiago, A. S.; Neto, C. P.; Vilela, C. Impact of effective alkali and sulfide profiling on Eucalyptus globulus Kraft pulping. Selectivity of the impregnation phase and its effect on final pulping results. J. Chem. Technol. Biotechnol. 2008, 251, 242-251.

(21) Ruiz, H. a; Ruzene, D. S.; Silva, D. P.; da Silva, F. F. M.; Vicente, A.; Teixeira, J. Development and characterization of an environmentally friendly process sequence (autohydrolysis and organosolv) for wheat straw delignification. Appl. Biochem. Microbiol. 2011, 164, 629-41.

(22) van Oss, C. J. V. A. N.; Good, R. J. Interfacial Lifshitz-van der Waals and polar interactions in macroscopic systems. Chem. Rev. 1988, 88, 927-941.

(23) Neves, L.; Pereira, M. A.; Mota, M.; Alves, M. M. Bioresource technology detection and quantification of long chain fatty acids in liquid and solid samples and its relevance to understand anaerobic digestion of lipids. Bioresource Technol. 2009, 100, 91-96.

(24) Santos, M.; Jiménez, J. J.; Bartolomé, B.; Gómez-Cordovés, C.; del Nozala, M. J. Bioresource technology detection and quantification of long chain fatty acids in liquid and solid samples and its relevance to understand anaerobic digestion of lipids. Food Chem. 2003, 80, 17-21. (25) Mandalari, G.; Faulds, C. B.; Sancho, A. I.; Saija, A.; Bisignano, G.; Locurto, R.; Waldron, K. W. Fractionation and characterisation of arabinoxylans from brewers' spent grain and wheat bran. J. Cereal Sci. 2005, 42, 205-212.

(26) Aurell, R.; Hartler, N. Kraft pulping of pine: Part 1-The changes in the composition of the wood residue during the cooking process. Sven Papperstidn 1965, 68, 59-68.

(27) Kanauchi, O.; Mitsuyama, K.; Araki, Y. Development of a functional germinated barley foodstuff from brewers' spent grain for the treatment of ulcerative colitis. J. Am. Soc. Brew. Chem. 2001, 59, 59-62.

(28) Kühbeck, F.; Back, W.; Krottenthaler, M.; Brew, J. I. Influence of lauter turbidity on wort composition, fermentation performance and beer quality-A review. J Inst Brew 2006, 112, 215-221.

(29) Dufour, J. P.; Alvarez, P.; Devreux, A.; Gerardi, W. Influence of the filtration procedure on the relationship between wort turbidity and its lipid content. Mschr. Brauwiss 1986, 39, 115-121.

(30) Klopper, W. J.; Tuning, B.; Vermeire, H. A. Free fatty acids in wort and beer. In Proceedings of the European Brewery Convention Congress; Elsevier Scientific: Amsterdam, 1975; pp 659-667.

(31) Anness, B. J.; Reed, R. J. R. Lipids in the brewery-A material balance. J. Inst. Brew. 1985, 91, 82-87.

(32) Stewart, G. G.; Martin, S. A. Wort clarity: Effects on fermentation. In Convention of the Master Brewers Association of the Americas; 2004; $18-26$

(33) Moo-Young, M.; Lamptey, J.; Robinson, C. W. Immobilization of yeast cells on various supports for ethanol production. Biotechnol. Lett. 1980, 2, 541-548.

(34) Shafrin, E. G.; Zisman, W. A. Constitutive relations in the wetting of low energy surfaces and the theory of the reaction method of preparing monolayers. J. Phys. Chem. 1960, 64, 519-524.

(35) Karagöz, P.; Erhan, E.; Keskinler, B.; Ozkan, M. The use of microporous divinyl benzene copolymer for yeast cell immobilization and ethanol production in packed-bed reactor. Appl. Biochem. Microbiol. 2009, 152, 66-73.

(36) Schmolke, H.; Demming, S.; Edlich, A.; Magdanz, V.; Büttgenbach, S.; Franco-Lara, E.; Krull, R.; Klages, C.-P. Polyelectrolyte multilayer surface functionalization of poly(dimethylsiloxane) (PDMS) for reduction of yeast cell adhesion in microfluidic devices. Biomicrofluidics 2010, 4, 044113.

(37) White, J. S.; Walker, G. M. Influence of cell surface characteristics on adhesion of Saccharomyces cerevisiae to the biomaterial hydroxylapatite. Antonie van Leeuwenhoek 2011, 99, 201-9. 